Filološki fakultet

\title{
KULTURE NA PUTU SVILE - AZERBEJDŽANSKA I SRPSKA PERSPEKTIVA
}

\section{Multikulturalizam u savremenom Azerbejdžanu}

Multikulturalizam je način života azerbejdžanskog naroda. Vekovima je narod koji živi uz zapadnu obalu Kaspijskog jezera pretvorio tolerantnost, trpeljivost i postovanje drugih religija i kultura u stil života. Danas je multikulturalizam u Azerbejdžanu uzdignut na nivo državne politike. Zbog toga je nije slučajno da je predsednik Azerbejdžana Ilham Alijev, prilikom održavanja 7. Globalnog foruma Alijanse civilizacija Ujedninjenih nacija, koji je održan u Bakuu u aprilu 2016, dao predlog da se 2016. godina proglasi godinom multikulturalizma. (Okrugli sto: Multikultularizam: iskustvo Azerbejdžana, 2016, 10-12.)

Prošlo je više od dvadest godina od kada se svet oslobodio pritiska konfrontacije iz vremena hladnog rata. Kolapsom Sovjetskog Saveza i nestankom Varšavskog pakta, činilo se da svet ulazi u jednu novu, prosperitetnu fazu, oslobođenu straha od masovnog uništenja. Međutim, mora se priznati da se nade u bezbedniji svet još uvek nisu ostvarile, već se, šta više situacija i pogoršala. Pretnju nuklearnim uništenjem civilizacije zamenile su nove opastnosti i izazovi, kao što su terorizam, separatizam, religijski i drugi oblici ekstremizma, regionalni sukobi, finansijsko-ekonomske krize, migracije i dugo. Svi ti problemi su postojali i ranije, ali sada u uslovima globalizacije, kada je svet postao mnogo više međusobno povezan i međusobno zavisan, oni su počeli da stiču univerzalni karakter, predstavljajući stvarnu pretnju za regionalnu i međunarodnu bezbednost. 


\section{Multikulturalizam kao državna politika Azerbejdžana}

Azerbejdžanska država, imajući dugogodišnje iskustvo, veruje da bi podsticanje multikulturalizma moglo da posluži kao odgovor, ako ne na sve, onda na mnoge od navednih problema, posebno u svetlu problema sa kojima se suočila Evropa zbog velikog priliva imigranata. Multikulturalizam podrazumeva etničku, jezičku i konfesionalnu raznovrsnost i raznovrsnost stilova života nekog društva. Ranije je ta raznovrsnost poticala od od istorijske heterogenosti stanovništva određenih država, dok je u poslednjih pola veka njen osnovni izvor postala migracija. U tom kontekstu, multikulturalizam se pojavio kao potreba da se migrantsko stanovništvo uključi u život države prijema. Poslednjih godina snažan priliv migranata usmerio se ka Zapadnoj Evropi. Kao rezultat tzv. „arapskog proleća“, koje je faktički razrušilo stabilnost u zemljama Bliskog istoka, zajedno sa ratom u Iraku i Siriji, vojnom intervencijom u Avganistanu i Libiji, ogroman broj migranata iz ovih područja, ali iz područja Magreba i SubSaharske Afrike, pohrlio je ka boljem životu u, prvenstveno, zemljama Evropske Unije.

Pored ratova i teška ekonomska situacija u ovom područjima takođe predstavlja izvor migracije. Poznat je odnos prema migrantima u zemljama Zapadne Evrope, bar zvanične politike Evropske Unije i vlada članica. Međutim, s druge strane $u$ istim tim razvijenim zemljama Zapada, u porastu je broj pristalica krajnje nacionalističke ideologije i ultradesničarskih političkih partija, a rasistički i šovinistički ispadi su učestali. Problem porasta takvih ideologija i pokreta, kao i porast nasilja zasnovanog na šovinizmu i rasizmu, znači i porast opastnosti dalje eskalacije, jer nije isključeno da će oni koji se odnose loše prema jednoj grupi ljudi, sutra ciljate i na druge grupe. $U$ mnogim zapadnim zemljama žive i migranti iz druih zemalja Istočne Evrope. Zbog toga aktuelni procesi mogu negativno da utiču na vrednosti tolerancije u svetu i da dovedu do haosa.

Azerbejdžanski multikulturalizam je preplitanje istorije, tradicije, vrednosti, socijalnog ponašanja, kao i državne politike. Multikulturalizam u Azerbejdžanu nije parola, već delovanje u praksi, u kojoj tokom mnogo godina predstavnici različitih etničkih i religijskih zajednica žive u miru i harmoniji. U Azerbejdžanu se multikulturalizam tokom mnogo vekova pretvorio u način života. Tokom ratova, krajem osamdesetih i početkom 
devedestih godina 20. veka, u sukobu sa Jermenijom oko Nagorno-Karabaha bilo je okupirano više od $20 \%$ teritorije Azerbejdžana, a više od milion ljudi su postali izbeglice i prinudno raseljena lica. Sa tih teritorija Azerbejdžanci su potpuno proterani. Kulturni i religijski spomenici su bili ili zbrisani sa lica zemlje ili teško oštećeni. Bez obzira na to, jermenska crkva koja se nalazi u centralnom i jednom od najlepših mesta u Bakuu, ostala je cela i netaknuta. U karakteru azerbejdžanskog naroda nije da ruši spomenike drugih kultura, naročito ne na Božiji hram, niti su Azerbejdžanci na taj sukob gledali kao na etnički ili religijski. (Okrugli sto: Multikultularizam: iskustvo Azerbejdžana, 2016)

Azerbejdžanska država snabdeva besplatnom energijom verske objekte svih konfesija koje istorijski postoje u Azerbejdžanu. Samo u Azerbejdžanu možete videti da mirno stoje jedna pored druge i sinagoga i džamija, kao i pravoslavna i katolička crkva. Svi ovi verski objekti se održavaju ili restauriraju na račun države. Od 2013. godine, azerbejdžanska država snabdeva besplatnim gasom i objekte svih veroispovesti i u susednoj Gruziji, uključujući tu i jermenske crkve. Azerbejdžan kao država daje svoj doprinos razvoju mulitkulturalizma u svetu i na regionalnom i na međunarodnom nivou.

\section{Baku proces}

Od 2014. godine u Bakuu je aktivan Međunarodni centar multikulturalizma. Nacionalizam, netolerancija, diskriminacija i podizanje zidova ne predstavljaju odgovor na globalne probleme. Put do njihovog rešenja je dijalog, poštovanje prema drugima i humanost. Azerbejdžan je multietnička država u kojoj je svaki narod ili nacionalna manjina sačuvao sopstvenu materijalnu i duhovnu kulturu, jezik, istoriju, mentalitet. Multikulturalne vrednosti Azerbejdžana nisu samo tekovina modernog doba, već svoje korene vuku iz istorije. U Azerbejdžanu je uspostavljen svojevrstan model tolerantnosti i multikulturnog dijaloga, a taj model može biti uzoran primer za mnoge države i multietničke regione sveta. Osnov nacionalne politike je utvrđen u samom Ustavu Republike Azerbejdžan, kojim je obezbeđena jednakost svih građana nezavisno od njihove etničke, reli- 
gijske ili rasne pripadnosti. Nacionalne manjine su predstavljene na svim nivoima vlasti. S druge strane, Azerbejdžan je jedna od retkih muslimanskih zemalja na svetu u kojima se istovremeno mole i šiiti i suniti, jedni pored drugih. Od sticanja nezavisnosti 1991. godine, Republika Azerbejdžan nastoji da promoviše prava nacionalnih manjina, te da im obezbedi adekvatan status i tretman u državi koja je preko $90 \%$ etinički homogena. Kao što je već navedeno u uvodnim poglavljima ovog rada, u Azerbejdžanu živi nešto manje od 10 miliona stanovinika (prema podacima iz 2014. godine -9.696 .210 , a prema popisu iz 2009. godine 8.922 .400 stanovnika). 91,6 \% stanovništva su Azerbejdžanci (Azeri), a oko 8,4\% stanovinštva su pripadnici nacionalinih manjina. $96,9 \%$ stanovništva pripada islamskoj religiji, a 92,5\% govori azerbejdžanski (azeri) jezik. Poređenja radi u Srbiji, većinskom srpskom stanovništvu prema poslednjem popisu pripada oko $88 \%$ ukupnog stanovništva. Međutim, Republika Azerbejdžan je institucionalno zaštitila prava nacionalinih manjina.

U Ustavu Republike Azerbejdžan jasno stoji da svaki pojedinac ima pravo da koristi maternji jezik i da svako ima pravo da bude vaspitavan i obrazovan, te da bude intelektualno angažovan u aktivnostima na maternjem jeziku, te da niko ne sme biti lišen prava da koristi maternji jezik. Ovako, široko, obezbedjena prava nacionalnih manjina mogu da se ostvare samo zbog toga što je Republika Azerbejdžan, kao sekularna država, prihvatila najveća civilizacijska dostignuća ostvarivanja i zaštite nacionalnih prava. lako sa ogromnom većinskom populacijom muslimanskog stanovništva, Azerbejdžan nije prihvatio državni sistem zasnovan na šerijatu i njegov odnos prema nacionalnim i verskim manjinama. (Okrugli sto: Multikultularizam: iskustvo Azerbejdžana, 2016)

Multikulturalizam, kao skup ideja o pravnom i političkom regulisanju etničkih različitosti, javlja se na zapadu od sedamdesetih do sredine devedestih godina dvadesetog veka. Nastale su kao potreba da se uspostavi mehanizam zamene starijih oblika etničke i rasne hijerahije novim odnosima u okviru demokratskog, građanskog društva. Multikulturalizam negira ranije ideje o unitarnim i homogenim državama. Suprotstavlja se etnocentrizmu i jača kulturnu različitost i integraciju kao osnovne faktore društva. Mnoge države su razvile sopstvene sisteme kako bi poboljšale uključivanje nacionalnih manjine i omogućile ostvarenje kulturne različitosti. Švedska, 
Kanada i Australija poznate su kao zemlje uzori po svojim modelima multikulturalizma. Od sredine devedesetih dolazi do naglog pada koncepta multikulturalizma. Oživljavaju ideje o izgradnji jedinstvene nacije unitarnog državljanstva, pa i povratka asimilacije. Ove ideje su prouzrokovane strahovima većinskih grupa koje su koncepte različitosti videle kao pretnju njihovom dotadašnjem načinu života. Politički uspon populističkih poreta u mnogim razvijenim i tolerantnim evropskim državama doveo je do slabljenja vere u multikulturalizam. Tako su se, npr. u tolerantnoj Danskoj, upsonom Danske narodne stranke, javile ideje i slogani „Danska Dancima“. Multikulturalna kriza je svoju kulminaciju doživela u Evropi tokom 2015. i 2016. godine usled nemogužnosti pronalaženja odgovarajućeg rešenja za problem sve većeg broja migranata. I sama kancelarka Nemačke, Angela Merkel, priznala je da je koncept multikulturalnosti doživeo neuspeh, što je prilično uzdrmalo Evropsku uniju. I tadašnji premijer Velike Britanije, je priznao da je državni multikulturaziam propao.

\section{Multikulturalizam i prava manjina u Azerbejdžanu}

Međutim, sa druge strane evropskog kontenta, onde gde se on spaja sa Azijom, multikulturalizam doživljava uspon. U Azerbejdžanu, vekovne kulturne različitosti i prisustvo mnogobrojnih naroda i religija stvorili su tolerantno i multikulturalno društvo. Azerbejdžan je razvojem i promocijom sopstvenog koncepta multikulturalizma, uspeo da stvori pozitivan i prepoznatljiv primer. Azerbejdžan je od davnina razvijao tradiciju poštovanja kulturnih različitosti zbog činjenice da je bio deo Puta svile. Prisustvo različitih etničih grupa na teritoriji Azerbejdžana stvorilo je i izrazitu lingvističku šarolikost. Tako su na ovom području prisutni jezici koji pripadaju različitim lingvističkim grupama: tursko-altajskoj, indoevropskoj, iranskoj, kavkaskoj i itd. Pored jezičke raznolikosti, pripadnici etničkih grupa koje žive u Azerbejdžanu imaju i drugačije religije, običaje, sisteme vrednosti, ali zajedničko za sve njih jeste to da su svojim kulturnim različitostima uticali na oblikovanje kulture Azerbejdžana. Tokom različitih istorijskih perioda stanovnici su ovog područja su dolazili u dodir sa različitim religijama, koje su doprinele formiranju multikulturalne klime. Tradicije i vrednosti 
velikih religija - zoroastrizma, islama, hrišćanstva i judaizma, imale su važan uticaj na formiranje interkulturnih odnosa kako u samom Azerbejdžanu, tako i u njegovom odnosu prema svetu. Usled zajedničke istorije i tradicije u Azerbejdžanu se nije razvio religijski ekstremizam.

Imajući u vidu sve navedeno, uopšte nije neočekivano da upravo iz Azerbejdžana potekne inicijativa za jačanje i oživljavanje poljuljanog koncepta multikulturalizma. Zbog toga je i vlada Azerbejdžana krajem 2008. godine pokrenula Baku proces, konferencijom ministara kulture Evrope i susednih regiona. Na ovu konferenciju su pozvani i ministri kulture islamskih država. Sledeće godine održana je konferencija ministara kulture islamskih država na kojoj su učestvovale i njihove kolege iz Evrope, kao i konferencija ministara kulture zemlja turkijskog govornog područja. Baku proces je zasnovan na planu Dijaloga civilizacija koju je usvojila Generalna skupština Ujedinjenih nacija (2001), UNESCO Konvenciji o zaštiti i promociji raznolikosti kulturnih izraza (2005), Islamskoj deklaraciji o kulturnoj različitosti (2004).

Baku proces ima za cilj unapređenje poštovanja kulturnih različitosti kroz dijalog i saradnju. Način rada Baku procesa je interaktivan i zasnovan na otvorenoj razmeni mišljenja između pripadnika različitog etničkog, verskog, kulturnog i jezičkog porekla i nasleđa koje žive u različitim delovima sveta, a na osnovu uzajamnog razumevanja i poštovanja. Ovaj proces promoviše dijalog i razumevanje među kulturama sa ciljem poboljšanja saradnje između različitih društva, posebno onih sa istoka i zapada. Inicijatori Baku procesa su svesni da oživljavanje multikulturalizma treba da obuhvati i saradnju između razlitičih tela, nacija i organizacija. Iz tog razloga, razvoj interkulturnog dijaloga se odvija kroz usklađena delovanja nadležnih međunarodnih i regionalnih organizacija, uz aktivno učešće država članica.

Ciljevi ovog procesa su u skladu sa glavnim osnivačkim ciljevima UNESCO-a: „usklađivanje različitih kultura, ali ne kroz uniformnost, nego kroz jedinstvo različitosti, jer ljudska bića nisu zatvorena u okviru jedne kulture i treba da uživaju u bogatstvu i različitosti svetskih kultura". U okrviru Baku procesa su pokrenute brojne nove inicijative, projekti i događaji sa ciljem očivanja i oživljavanja glavnih vrednosti multikulturalizma. Akcenat se stavlja na umetnost, kulturu, kulturno nasleđe, a radi njihovog efikasnijeg integrisanja u proces realizacije interkulturnog dijaloga, razu- 
mevanja i poštovanja između različitih kultura. S tim ciljem, pokrenuto je nekoliko kulturnih inicijativa. Uspešan rad Baku procesa nastavljen je organizacijom tri foruma o interkulturnom dijalogu (2011, 2013. i 2015. godine). Interkulturni dijalog je odabran za glavnu temu foruma usled sve češće pojave u međunarodnoj zajednici da se različiti odnosi između država posmatraju kao odnosi koje određuju ne politički interesi i ciljevi, već rasa, religija ili druge osobine. Poboljšanje odnosa među državama i svaki vid buduće saradnje na bilo kom novou „mora podrazumevati rušenje takvih stereotipa putem dijaloga i zajedničkog delovanja pojedinaca, nevladinih organizacija, vladinih i međuvladinih organizacija“.

Bela knjiga Saveta Evrope je definisala interkulturalni dijalog kao „otvorenu i dostojanstvenu razmenu mišljenja“. Svaki od tri foruma je poslao snažne poruke o potrebi oživljavanja multikulturalizma i značaju unapređenja kulturne saradnje. Prvi forum je održan u Bakuu 2011. godine. Predsednik Azerbejdžana Ilham Alijev tom prilikom je poručio da se „multikulturalizam ne može smatrati kao nešto što nema budućnosti. Naprotiv. Ako bismo odustali od njega, situacija u svetu bi se mogla značjno pogoršati (...) i alternative bi bile diskriminacija, ksenofobija, antisemitizam, islamofobija." Forum je istakao interkulturni dijalog kao jedan od najhitnijih izazova sa kojima se svet danas suočava i istakao političke i praktične aspekte intekulturalnog dijaloga.

Drugi forum o interkulturalnog dijalogu je održan u Bakuu, od 29. maja do 1. juna 2013. godine uz saradnju vlade Azerbejdžana sa UNESCom, drugim organizacijama UN, Islamskom organizacijom za obrazovanje i kulturu i Savetom Evrope. Forum je imao veliki odjek i okupio je 550 učesnika iz osamdeset zemalja. Treći forum o interkuluralnom dijalogu održan je 18. i 19. maja 2015. godine u Bakuu. Održavanje ovog foruma je predstavljao uvod u obeležavanje Svetskog dana kulturne raznolikosti kroz dijalog i razvoj (21. maja) kao i obeležavanje desetogodišnjice donošenja Konvencije o zaštiti i promociji raznolikosti kulturnih izraza (donete 2005. godine). Četvrti svetski forum o interkulturalnom dijalogu je održan u Bakuu 5. i 6. maja 20107. godine. Forum je razmatrao teme kao što su uloga vere, religija, migracija, bezbednosti, sporta, obrazovanja, umetnosti, održivog razvoja, nasilnog ekstremizma, biznisa u izgradnji poverenja i saradnje između kultura i civilizacija. Učestvovalo je preko dve stotine 
predstavnika iz različitih zemalja, međunarodnih organizacija, predsednika vlada, ministara, visokih službenika, kulturnih poslenika, ambasadora dobre volje, eksperata i sl.

Značajan korak u daljem razvoju multikulturalizma i međunarodne kulturne saradnje predstavlja i osnivanje Međunarodnog centra za multikulturalizam 2014. godine u Bakuu, kao izraz „potrebe da se promoviše Azerbejdžan širom sveta kao primer tolerancije i da se analizom usklađenosti društvenih, političkih i drugih aspekata multikulturni modeli drugih zemalja uporede sa multikulturnim orkuženjem Azerbejdžana". Vreme od osnivanja Centar je iskoristio da razgrana svoju delatnost te ima kancelarije u Nemačkoj, Italiji, Portugalu, Rusiji, Izraelu i Moldaviji. Centar za multikulturalizam pre svega promoviše interakciju između kultura različitih regiona i razvoj odnosa uzajamnog poštovanja i poverenja među narodima i religijama. Koliki značaj pridaje Azerbejdžan razvoju multikulturalizma jeste i podatak da je 11. januara 2016. godine, predsednik Azerbejdžana Ilhan Alijev potpisao dekret kojim je 2016. godine proglašena godinom multikulturalizma u Azerbejdžanu.

Multikulturalizam je svetska realnost. Danas u svetu postoji samo desetak monoetničkih država u kojima živi tek oko 0,5\% svetske populacije, odnosno grubo rečeno tek oko 35 miliona ljudi. Višejezičke i multientničke države su stvarnost na svetskom nivou. Kako države ne mogu funkcionisati same po sebi, to im je potrebna saradnja i podrška drugih, kao i razmena ideja i iskustava. $S$ druge strane, ljudi putuju u druge države i dolaze u dodir i upoznaju druge kulture, religije, običaje. Iz tog razloga multikulturalizam ne može biti prevaziđen. Kultura i kulturno nasleđe povezuju pojedince i državu.

Baku proces, putem kulture i kulturne baštine, oživljava političku viziju zasnovanu na univerzalnim, nedeljivim vrednostima ljudskih prava, demokratije i vladavine prava unutar evropskog kontinenta i između Evrope i susednih regiona. Svojim prisutpom približavanju kultura i razvoja kulurne saradnje i interkulturalnog dijaloga, daje nadu za bolje međusobno razumevanje i političku saradnju između država Istoka i Zapada u budućnosti. Oživljavanjem multikulturalizma, međusobne saradnje, razumevanja i poštovanja kulturnih razlika svet može postati bolje mesto. Multikulturalizam predstavlja jednako i uzajamno poštovanje prema razli- 
čitim kulturama u društvu, kao i politiku promovisanja održavanja kulturne raznolikosti. Multikulturalizam se fokusira na interakciju i komunikaciju između različitih kultura. Sa druge strane, multikulturalizam se ne odnosi samo na suživot ljudi različitih kulturnih, verskih i etničnik pripadnosti, već je međusobno poštovanje, kao koncept, potpuno samo kada je podržano i od strane javne politike. Ukoliko postoji samo multikulturalna situacija, a nema javne politike da je podrži, multikulturalizam tu zapravo i ne postoji i obrnuto.

Azerbejdžan, iako zemlja sa većinskim muslimanskih stanovništvom, na raskrsnici Evrope i Azije, postala je model zemlje koja prosavlja multikulturalizam, međureligijski suživot i toleranciju. Predstavnici različitih religija, nacionalnosti i kultura su kroz istoriju Azerbejdžana živeli i danas žive u miru i srađuju jedni sa drugima na osnovama uzajamnog poštovanja. Azerbejdžanci su uvek čuvali ovu tradiciju živom i očuvali je. Ova vizija čini Azerbejdžan zemljom koja ulaže u multikulturalizam kao alternativno rešanje za inkluziju i kulturnu izolaciju, separatizam, radikalizam, ekstremističke ili nasilne pretnje. Ova tradicija daje zemlji osećaj sigurnosti, solidarnosti i jedinstva, čini je otvorenijom za razlike i različitosti. (Okrugli sto: Multikultularizam: iskustvo Azerbejdžana, 2016)

Ukupan broj stanovnika Azerbejdžana po podacima iz 2014. godine iznosi 9.696.210 stanovnika (poslednji zvanični popis iz 2009. godine beleži broj od 8.922.400 stanovnika). Preko 90\% stanovništva čine Azerbejdžanci (Azeri) i taj procenat iznosi 91.6\%. Slede Lezgini (2\%), Rusi (1.3\%), Jermeni (1.3\%), Tališi (1.3\%) i ostale brojčano manje manjinske etničke grupe, poput Tata, Avara, Gruzijaca i Aškenazi Jevreja (dakle manjine su zastupljene sa 8.4\%). Većinska verska pripadnost stanovništva (96.9) je islamska, dok 92.5\% ukupnog stanovništva Azerbejdžana govori azerbejdžanski (azeri) jezik. (http://www.azernews.az/nation/91533.html)

Od sticanja nezavisnosti pa do današnjih dana, Republika Azerbejdžan nastoji da promoviše prava nacionalnih manjina, te da im obezbedi adekvatan status i tretman u državi koja je preko $90 \%$ etnički homogena. U članu 21, odeljka II, koji reguliše upotrebu službenog jezika u Ustavu Republike Azerbejdžan se navodi:

- „I. Azerbejdžanski jezik je zvanični jezik Republike Azerbejdžan.

- II. Republika Azerbejdžan staraće se o razvoju azerbejdžanskog jezika. 
- III. Republika Azerbejdžan će garantovati slobodnu upotrebu i razvoj drugih jezika koje govore narodi“.

Takođe, u članu 45. („Pravo na upotrebu maternjeg jezika“) odeljka III Ustava Republike Azerbejdžan navodi se:

- I. Svaki pojedinac ima pravo da koristi maternji jezik. Svako ima pravo da bude vaspitavan i obrazovan, te da bude intelektualno angažovan u aktivnostima na maternjem jeziku.

- II. Niko ne sme biti lišen prava da koristi maternji jezik". (http:// www.mfa.gov.az/en/content/114)

Na osnovu ovog pregleda manjinskih grupa u Azerbejdžanu, očigledno je da ima etničkih zajednica koje su na našim prostorima veoma slabo izučavane. Jedan od takvih naroda su Lezgini, kavkaski narod, koji pretežno živi u Rusiji, odnosno u autonomnoj republici Dagestan, u kojoj čini $13 \%$ stanovništva. Lezgini su većinom islamske veroispovesti, a govore lezginskim jezikom, koji spada u dagestansku grupu severnokavkaske porodice jezika. Po Lezginima je nazvan i vrlo popularan ples među kavkaskim narodima - lezginka. Ukupno ih ima oko 434.000, od toga u Rusiji 217.000, a u Azerbejdžanu 178.000. Tališi su etnička grupa koja broji 76800 ljudi, koji žive u kompaktnoj zajednici u južni delovima Azerbejdžana. Jezik je tališki, koji pripada iranskoj grupoži indo-evropske jezičke porodice, ali svi pripadnici ove etničke zajednice govore i azerbejdžanski. Etnička zajednica Avara broji 50.900 duša, koji žive u severnim oblastima zemlje. Govore avarski jezikom koji pripada dagestanskoj grani kavkaskih jezika. Takođe sve govore i azerbejdžanski. Turci-Mešketijanci broje 43.400 ljudi i žive u severnim, kao i nizinskim predelima Azerbejdžana. Zvanični jezik im je azerbejdžanski. Tatara ima 30.000 hiljada, i oni žive u gradskim sredinama u Azerbejdžanu. Govore tatarskim jezikom, koji pripada Turskoj jezičkoj porodici, a služe se i ruskim jezikom. Čakuri broje 15900 ljudi i žive u Zakatalskoj oblasti Azerbejdžana. Zvanični jezik im je čakurski, koji pripada jugoistočnog grupi Kavkaskih jezika, dagestanskoj grapni. Takođe svi govore i azerbejdžanski. Zajednica Tata broji 10900 ljudi, koji žive u severnim oblastima. Govore tatskim jezikom, koji pripada iranskoj jezičkoj grupi; svi govore kao i azerbejdžanski. Udina ima 4100, i oni takođe žive u severnim oblastima. Jezik komunikacije je udinski, koji pripada degestanskoj grani kavkaske jezičke porodice. Svi pripadnici ove etničke zajednice govore i 
azerbejdžanski. (http://www.academia.edu/10576325/Ethnic_Minorities_in_Azerbaijan)

Azerbejdžan vidi multikulturalizam kao akcioni sistem od značaja za razvoj čovečanstva u budućnosti, jer u eri globalizacije, ljudske interakcije među kulturama su postale neophodnost. Različite tradicije i kulture moraju da se prepliću radi solidarnosti i jedinstva, radi večnog mira i blagostanja, jer različite kulture žive u jednom svetu, sviđalo se to njima ili ne. Bilo je nekoliko pokušaja da se stvore veštački narodi kao što su čehoslovački, sovjetski, jugoslovenski i sl. lako su ove unije jedan određeni vremenski period veoma uspešno funkcionisale, ti pokušaji su propali. Neki narodi su ostali vekovima pod uticajem različitih kultura, religija ali su sačuvali svoj identitet. Teritorije mogu biti okupirane, ali ne i kultura, umovi i srca. Svaka nacija na svetu ima odgovornost da čuva i promoviše svoju tradiciju, kulturno nasleđe, moralne vrednosti. Različite kulture moraju znati jedne druge bolje, ne da bi se usredsredile na razlike koje razdvajaju, već na sličnosti koje spajaju. Nije neuobičajeno da religiozni i inteligentni ljudi razumeju jedni druge mnogo lakše. Oni mogu da predstavljaju različite religije, nacije, ali oni se međusobno razumeju, govore o istim vrednostima i principima, uvek podržavaju mir i dijalog. Mali narodi su veoma podložni da uđu u konflikte koje podstiču velike sile. Ukoliko „mali“ ne uspeju da razumeju jedni druge i da prihvate razlike i poštuju kulturnu raznolikost, onda strane sile to mogu zloupotrebiti radi ostvarenja svojih interesa za eskalacije sukoba, separatizam, ekstremizam, radikalizam. I rezultat je uvek patnja „malih“. Multikulturalizam i tolerancija su posebno aktuelni i neophodni za Balkan i Kavkaz, jer su ovi regioni naseIjeni različitim etničkim grupama koje pripadaju i različitim religijama. Multikulturalizam je sada jedinstveni obrazac ka prosperitetu i stabilnosti, koji može dovesti do velikih rezultata, uključujući rasnu i etničku harmoniju, uzajamno poštovanje, napredak, prijateljstvo, mir, uzajamno razumevanje. Azerbejdžan je jedna od retkih zemalja koja ne samo da razgovara i disktuje o multikulturalizmu, već preduzima i neophodne korake za dalje unapređenje mulitukturalnih vrednosti širom sveta. Multikulturalizam je način života u Azerbejdžanu i on se ponosi time. (Okrugli sto: Multikultularizam: iskustvo Azerbejdžana, 2016) 